\title{
BSPD calls for equality of access to specialist care for 0-16s with highest dental needs
}

New research into the UK's dental specialist workforce suggests that the number of specialists in paediatric dentistry should be trebled to meet the needs of children aged $0-16 .^{1}$

There are currently 227 specialists in paediatric dentistry working in the UK and David Auld, Chairman of the British Society of Paediatric Dentistry's specialists' branch, says urgent steps should be taken to incentivise specialist training.

Auld said: 'You can see clearly on the map created by the study's authors that there are areas of relatively good access very close to areas with much poorer specialist to child population ratio, often in more remote areas.

'Children living in rural areas will have clinical needs just as children in urban populations do, although the specific needs aren't looked at in this study. I hope that individual health boards and regional NHS teams will look closely at these inequalities and take action to improve access for children to specialist-led care where it is required.'

The concept of developing specialistled services is supported by BSPD which believes that by appointing consultants and specialists to leadership roles in areas where access is poor, the workforce can be up-skilled, developed and supported.

Urshla Devalia, BSPD's Honorary Secretary and a Consultant in Paediatric Dentistry said that there are already parts of the country where specialists are being given a leadership role with a mandate to support GDPs in rural practices. However, more specialists are needed as well as more innovative models of care.

Devalia added: 'There is no shortage of dental graduates wanting to train as a paediatric dentist but the recruitment system and the absence of collaboration between employers are barriers to developing the paediatric dental workforce.

'We need to be working creatively and collaboratively to ensure that every child and young person is able to access highest quality, specialist-led paediatric dental services.'

\section{Reference}

1. Jo O, Kruger E and Tennant M. Dental specialist workforce and distribution in the United Kingdom: a specialist map. Br Dent $J$ 2021; doi. org/10.1038/s41415-021-3167-9.

\section{Workshop date}

\section{announced}

The British Dental Editors and Writers Forum (BDEWF) Workshop for New Authors and Peer Reviewers is back for 2021.

Postponed in 2020 due to the pandemic, this year's workshop - co-chaired by Professor Kenneth Eaton and Stephen Hancocks OBE - will take place on Tuesday 2 November at the British Dental Association at 64 Wimpole Street in London. It is $£ 40$ for BDEWF members, $£ 65$ for non-BDEWF members and $£ 20$ for full-time students.

To book your place or for further information, please contact stephen. hancocks@bda.org.

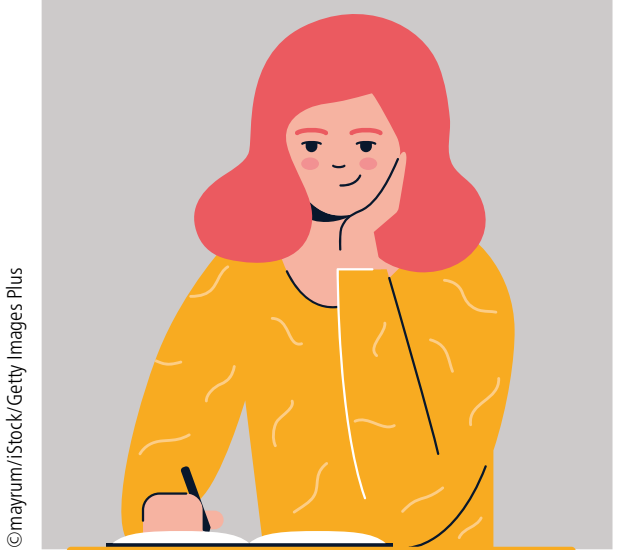

\section{Dentists: Scottish Government must apply full}

\section{pay award}

The British Dental Association has called on the Scottish Government to confirm that the recently announced $3 \%$ pay award for dentists will be applied to practitioners' overall remuneration package to avoid front line staff potentially being left out of pocket and practices struggling to invest to improve care.

Historically in Scotland the recommended uplift has not applied to all dentists' allowances and payments, meaning the overall awards often fall short of the pay review body's recommendations.

Last year the Scottish Government did not apply the recommended $2.8 \%$ uplift to practice allowances - which make up around $16 \%$ of practice income -leaving an overall increase of less than the review body's recommendations. The $\mathrm{BDA}$ estimates that the net award for that year was around $2.3 \%$.

While one-off support to fund improvements in ventilation has been offered by the Scottish Government, NHS dentists do not routinely receive capital investment. These earnings serve to fund all improvements in equipment, training, and facilities for NHS practices.

Scottish Government officials have stated they will provide details of how the package

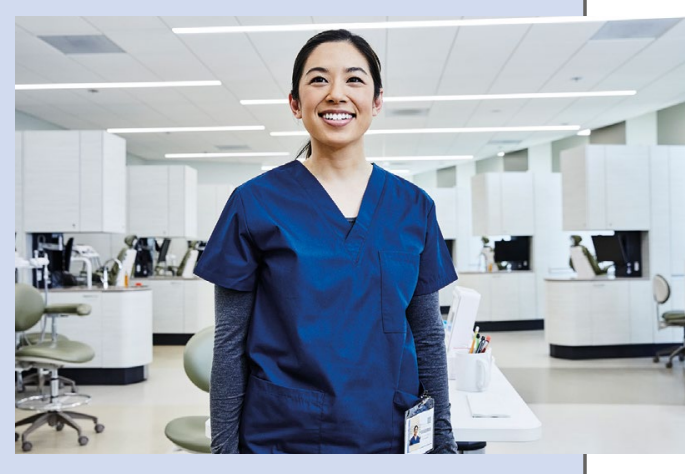

will operate in due course. The BDA is calling for the $3 \%$ uplift to be applied to the full remuneration package.

David McColl, Chair of the British Dental Association's Scottish Dental Practice Committee said: 'The Scottish Government's announcement has left key questions unanswered.

'This uplift will do little to correct a decade of austerity, and not all of this increase may actually reach dentists, who rely on their earnings to invest in their practices.

'In the recent election, Ministers put dentistry front and centre in their pitch for government. If they are going to deliver on their promises they shouldn't be shortchanging front line practitioners.' 